\title{
THE APPLICATION OF THE GENETIC ALGORITHM TO MULTI-CRITERIA WAREHOUSES LOCATION PROBLEMS ON THE LOGISTICS NETWORK
}

\author{
Mariusz IZDEBSKI ${ }^{*}$, Ilona JACYNA-GOŁDA ${ }^{2}$, Mariusz WASIAK ${ }^{3}$, Roland JACHIMOWSKI ${ }^{4}$, \\ Michał KŁODAWSKI ${ }^{5}$, Dariusz PYZA ${ }^{6}$, Jolanta ŻAK ${ }^{7}$ \\ ${ }^{1,3-7}$ Faculty of Transport, Warsaw University of Technology, Poland \\ ${ }^{2}$ Faculty of Production Engineering, Warsaw University of Technology, Poland
}

Received 10 May 2017; accepted 23 September 2017

\begin{abstract}
This paper presents multi-criteria warehouses location problem in the logistics network. In order to solve this problem the location model was developed. The limitations and optimization criteria of the model were determined. Optimization criteria refer to transportation costs, costs associated with warehouses, e.g.: local taxes, expenditure on starting the warehouse, the constant costs, the labour force costs, the purchase costs of the additional land for the expansion, the transition costs of the raw material via the warehouses. The final location of warehouse facilities was obtained using a genetic algorithm. The genetic algorithm was developed in order to solve the multi-criteria warehouses location problem. This paper describes the stages of the genetic algorithm i.e. the stage of designating the initial population, the crossover and mutation process, the adaptation function. In this paper, the process of calibration of this algorithm was presented. The results of the genetic algorithm were compared with the random results.
\end{abstract}

Keywords: genetic algorithm, multi-criteria warehouses location problems, optimization, matrix crossover, adaptation function.

\section{Notations}

Variables and functions:

$V$ - set of numbers of spot elements of the logistical network: suppliers, warehouses, production companies;

$D S$ - set of numbers of suppliers;

$\alpha(v)$ - the mapping which assigns the number of elements of the logistic network to object type;

$M S$ - set of numbers of warehouses;

$P$ - set of numbers of production companies (recipients);

$H$ - set of number of types of the raw material;

$T$ - set of numbers of working days;

$P O J$ - set of types of vehicles of different capacity;

$D 1$ - distance matrix in relations: suppliers - warehouses;

D2 - distance matrix in relations: suppliers - enterprises;

D3 - distance matrix in relations: warehouses - enterprises;
D4 - distance matrix in relations: warehouses - warehouses;

DY1 - distance of the warehouses from the railway infrastructure;

$D K 1$ - distance of the warehouses from the road infrastructure;

Q1 - volume of deliveries from suppliers on a given working day;

Q2 - demand volume of enterprises on particular working days;

Q3 - volume of the raw material, which is stored in the warehouses on a given working day;

Q4 - maximal processing capacity for each warehouse;

$U M Z$ - minimal volume of the raw material, which decides on selection of the warehouses added to the logistic network;

POJZ - warehouses capacity;

$N$ - vehicle capacity in pallet units;

$V E H$ - number of vehicles of a given capacity, which transport the raw material between particular points of the logistic network;

${ }^{*}$ Corresponding author. E-mail: mizdeb@wt.pw.edu.pl 
$K Z P$ - the unit cost of fuel;

$K Z$ - transition costs of the raw material via the warehouses;

$C$ - transport costs of load unit per distance unit between particular facilities of the logistic network;

$J K M$ - storage costs;

$K L Z$ - taxes in the place of warehouse's location;

$K L Z 1$ - expenditure on starting the warehouse in a given location;

$K L Z 2$ - the running costs for each warehouse;

$K L Z 3$ - the labour force costs for each warehouse;

$K L Z 4$ - the purchase costs of the additional land for the expansion;

$Y 11$ - the decision variable determines the volume of cargo, which flows between suppliers - warehouses;

Y12 - the decision variable determines the volume of cargo, which flows between suppliers - production companies;

$Y 13$ - the decision variable determines the volume of cargo, which flows between warehouses - production companies;

Y14 - the decision variable determines the volume of cargo, which flows between warehouses -warehouses;

$Y 1$ - the decision variable determines the warehouse location;

$F 1(Y 11, Y 12, Y 13, Y 14)$ - the criterion of transportation costs between the facilities of the logistic network;

F2(Y11,Y14) - the criterion of the transition of the raw material via the warehouses;

$F 3(Y 11, Y 12, Y 13, Y 14)$ - the criterion of the fuel costs;

$F 4(Y 1)$ - the criterion of the additional costs associated with warehouses, e.g.: local taxes;

F5(Y1) - the criterion associated with the distance of warehouses from the railway infrastructure;

F6 (Y1) - the criterion associated with the distance of warehouses from of road infrastructure;

$M(t, h)$ - the structure of the chromosome;

$F(k, t, h)$ - the adaptation function;

F1min - the minimum value of the criterion function $F 1(Y 11, Y 12, Y 13, Y 14)$ from the whole population in a given iteration of algorithm;

$F 1(k, t, h)$ - the value of the criterion function $F 1(Y 11, Y 12, Y 13, Y 14)$ for $k$ - the structure of the chromosome;

F2min - the minimum value of the criterion function $F 2(Y 11, Y 14)$ from the whole population in a given iteration of algorithm;

$F 2(k, t, h)$ - the value of the criterion function $F 2(Y 11, Y 14)$ for $k$ - the structure of the chromosome;

F3min - the minimum value of the criterion function $F 3(Y 11, Y 12, Y 13, Y 14)$ from the whole population in a given iteration of algorithm;
$F 3(k, t, h)$ - the value of the criterion function $F 3(Y 11, Y 12, Y 13, Y 14)$ for $k$ - the structure of the chromosome;

F4min - the minimum value of the criterion function $F 4(Y 1)$ from the whole population in a given iteration of algorithm;

$F 4(k, t, h)$ - the value of the criterion function $F 4(Y 1)$ for $k$ - the structure of the chromosome;

F5min - the minimum value of the criterion function $F 5(Y 1)$ from the whole population in a given iteration of algorithm;

$F 5(k, t, h)$ - the value of the criterion function $F 5(Y 1)$ for $k$ - the structure of the chromosome;

F6min - the minimum value of the criterion function $F 6(Y 1)$ from the whole population in a given iteration of algorithm;

$F 6(k, t, h)$ - the value of the criterion function $F 6(\mathrm{Y} 1)$ for $k$ - the structure of the chromosome;

$\operatorname{DIV}(t, h)$ - the matrix, which comprises rounded up average values from both parents;

$\operatorname{REM}(t, h)$ - the matrix, which contains the information whether the rounding up was indeed necessary.

\section{Introduction}

The problem of warehouses location is an issue that is generally known and widely discussed in the context of decision-making problems, which occur on the stage of constructing the logistic network in any company (Akinc, Khumawala 1977; Brandeau, Chiu 1989; Özcan et al. 2011). The classical issue of warehouse location is defined in literature (Sharma, Berry 2007) as the Capacitated Warehouse Location Problem (CWLP). In this class of problems, the structure of the transport and logistics network consists of warehouse facilities and customers. The main objective in the general warehouses location problem is to find such a location of warehouse facilities for which the costs arising from forwarding a specific volume of goods to the customers via warehouses are as low as possible. The transport cost depends on the volume of goods, which are carried between warehouses and customers and also on the distance between them, and hence it is also necessary to set out volumes of carried goods. Limitations, on the other hand, arise from satisfying the needs of all customers and the capacitive limit for the dispatch of goods from the given warehouse facility. If no capacity limitation is imposed, an uncapacitated warehouse location problem is considered (Khumawala 1973).

The warehouses location problem depends on the complexity of the logistics network. The logistic network is a set of elements (items): suppliers, manufacturers, recipients, etc., which are linked with each other in a diverse way (the direct or indirect relationships between facilities). Depending on the number of intermediate points on the transport route, the network structure may be single-level (Özcan et al. 2011) (the direct relationship: suppliers - re- 
cipients) or multi-level (Ambroziak et al. 2006; Geoffrion, Graves 2010; Sharma 1991) (the indirect relationship: suppliers - intermediate points - recipients) which is called a hierarchical one. One of the characteristic features of the multi-level network is that materials have to flow from suppliers via subsequent levels to recipients. In the multilevel network, there are intermediate points such as various types of warehouses, reloading terminals and logistic centres.

The problem of warehouse situation may be generally reviewed from two basic viewpoints. The first one concerns selecting the place where a new warehouse is to be erected (Akinc, Khumawala 1977; Sharma, Berry 2007). Basically, in such a case potential locations for the construction of a new warehouse are determined. The second aspect includes a review of the selection of warehouse locations from the already existing facilities, which points to a reconfiguration of the logistic network for various types of enterprises (Jacyna-Gołda 2013).

The warehouse location problem in the logistics network is multi-criteria optimization problem that depends on quantitative and qualitative criteria. In this issue, the following criteria may be distinguished (Jacyna-Gołda et al. 2016; Demirel et al. 2010):

- Costs: labour costs, transportation costs, storage costs, taxes. Labour costs change with respect to the life conditions at alternative locations. Transportation cost depends on the size of the cargo transported between facilities of the logistics network, distances between the warehouse and facilities within the network. Storage costs and taxes are different according to the regions.

- Labour characteristics: skilled labour and availability of labour force. This criterion determines the state of qualified labour at a given location. Skilled labour defines the personnel with appropriate qualities to perform work. The skilled labour and availability of labour force may be different according to the regions.

- Infrastructure: existence of modes of transportation, quality and reliability of modes of transportation. Existence of modes is understood as the availability of different transportation types in the given location, e.g. railway. Quality and reliability of modes of transportation refers to timely deliveries.

- Market: proximity to customers, suppliers or producers. These factors in large degree influence the transportation costs.

The presented criteria emphasis the complexity of the problem arising from location of storage facilities and in a certain way determine the application of the multi-criteria decision-making assistance in selection of the optimum solution (Wasiak et al. 2016; Dey et al. 2016; Merkisz-Guranowska, Pielecha 2014; Zieja et al. 2015; Gołda, Manerowski 2014; Jacyna 1999; Jacyna, Wasiak 2015; Podviezko 2012). The multi-criteria decision-making problem of warehouses location is solved by TOPSIS, ELECTRE, Grey Theory methods (Özcan et al. 2011), fuzzy logic (Dey et al. 2016) or Choquet integral (Demirel et al. 2010).
The most frequently used method of solving singlecriteria location problems in available literature is the method of distance minimising, which is also called network grid method or the gravity method. Drawbacks of the smallest distance method comprise the following:

- Lack of possibility of concurrent determination of location areas for several planned warehouse facilities (single-facility method);

- Possibility of taking only a single criterion into account (single-criteria method);

- Lack of possibility of taking into account the actual course of transport routes (windy roads or location of bridges);

- Considerable likelihood of finding a solution that is extremely difficult to interpret (e.g. obtaining location of a facility on the nature reserve site, on a densely built-up land, on a large lake - where at the edge of an inadmissible land the planned facility is to be erected in such a situation).

The main aim of this article is to develop the tool, which may be used in the multi-criteria warehouses location problem in the logistic network. In order to solve the multi-criteria warehouses location problem the genetic algorithm was developed. The application of the genetic algorithm in the multi-criteria warehouses location problem was dictated by the fact that the authors do not find the application of this algorithm in the examined multicriteria problem. Genetic algorithms belong to a group of heuristic algorithms, which do not guarantee the optimal solution, but only close to the optimal solution so-called sub-optimal. Despite this inconvenience genetic algorithms are a practical tool for optimization and are used in a variety of complex decision problems, e.g. vehicles routing problems (Szczepański et al. 2014; Lewczuk 2015), single-criteria warehouses location problem (Izdebski et al. 2016). The complexity of the problem of locating warehouse facilities limits the use of accurate methods to find optimal solutions and allows to accept sub-optimal solutions.

\section{Formulation of the problem}

For mathematical formulation of the problem, the following assumptions are made:

- The mathematical model of warehouses location refers to the logistic network which consists of suppliers, warehouses and production companies (recipients);

- The suppliers provide different types of the raw material to the production companies on a given working day;

- The production capacity of suppliers on a given working day meet the needs of production companies.

In accordance with above list of assumptions proposed optimization task takes the following form:

$$
\begin{aligned}
& -V=\left\{v: v=1,2, \ldots, v^{\prime}, \ldots, V\right\} ; \\
& -\alpha(v)=\{0,1,2\} ;
\end{aligned}
$$


- DS $=\{v: \alpha(v)=0$ for $v \in V\}$

- MS $=\{v: \alpha(v)=1$ for $v \in V\}$;

- $P=\{v: \alpha(v)=2$ for $v \in V\}$;

- $H=\{1, \ldots, h, \ldots, H\}$;

- $T=\{1, \ldots, t, \ldots, T\}$;

- POJ $=\{1, \ldots, p o j, \ldots P O J\}$;

- $D 1=\left[d 1\left(v, v^{\prime}\right): d 1\left(v, v^{\prime}\right) \in R^{+}\right.$, $\left.v \in D S, v^{\prime} \in M S\right]$;

- D2 $=\left[d 2\left(v, v^{\prime}\right): d 2\left(v, v^{\prime}\right) \in R^{+}\right.$, $\left.v \in D S, v^{\prime} \in P\right]$;

- D3 $=\left[d 3\left(v, v^{\prime}\right): d 3\left(v, v^{\prime}\right) \in R^{+}\right.$, $\left.v \in M S, v^{\prime} \in P\right]$;

- D4 $=\left[d 4\left(v, v^{\prime}\right): d 4\left(v, v^{\prime}\right) \in R^{+}\right.$, $\left.v \in M S, v^{\prime} \in M S\right]$;

- DY1 $=[d y 1(v): v \in M S]$;

- DK1 $=[d k 1(v): v \in M S]$;

- Q1 $=\left[q 1(v, h, t): q 1(v, h, t) \in R^{+}\right.$, $v \in D S, h \in H, t \in T]$;

- Q2 $=\left[q 2(v, h, t): q 2(v, h, t) \in R^{+}\right.$, $v \in P, h \in H, t \in T]$;

- Q3 $=\left[q 3(v, h, t): q 3(v, h, t) \in R^{+}\right.$, $v \in M S, h \in H, t \in T]$;

- $Q 4=\left[q 4(v, h, t): q 4(v, h, t) \in R^{+}\right.$, $v \in M S, h \in H, t \in T]$;

- UMZ $=\left[\delta(v, h): \delta(v, h) \in R^{+}, v \in M S, h \in H\right]$;

- POJZ $=\left[\operatorname{pojz}(v): \operatorname{pojz}(v) \in R^{+}, v \in M S\right]$;

- $N=\left[n(p o j): n(p o j) \in R^{+}, p o j \in P O J\right]$;

- VEH $=\left[v e h\left(v, v^{\prime}, p o j\right): v e h\left(v, v^{\prime}, p o j\right) \in R^{+}\right.$, $\left.v, v^{\prime} \in V \times V, p o j \in P O J\right]$;

- KZP $=\left[k z p(p o j): k z p(p o j) \in R^{+}, p o j \in P O J\right]$;

- $K Z=\left[k z(v, h): k z(v, h) \in R^{+}, v \in M S, h \in H\right]$;

- $C=\left[c\left(v, v^{\prime}, h\right): c\left(v, v^{\prime}, h\right) \in R^{+}\right.$, $\left.v, v^{\prime} \in V \times V, h \in H\right]$;

- JKM $=\left[j k m(v, h): j k m(v, h) \in R^{+}\right.$, $v \in M S, h \in H]$;

- KLZ $=\left[k l z(v): k l z(v) \in R^{+}, v \in M S\right]$;

- $K L Z 1=\left[k l z 1(v): k l z 1(v) \in R^{+}, v \in M S\right]$;

- KLZ2 $=\left[k l z 2(v): k l z 2(v) \in R^{+}, v \in M S\right]$;
- KLZ3 $=\left[k l z 3(v): k l z 3(v) \in R^{+}, v \in M S\right]$;

- KLZ4 $=\left[k l z 4(v): k l z 4(v) \in R^{+}, v \in M S\right]$,

one should find the values of decision variables:

- Y11 $=\left[y 11\left(v, v^{\prime}, h, t\right): y 11\left(v, v^{\prime}, h, t\right) \in R^{+}\right.$ $\left.v \in D S, v^{\prime} \in M S, h \in H, t \in T\right]$;

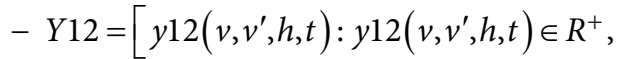
$\left.v \in D S, v^{\prime} \in P, h \in H, t \in T\right]$;

- Y13 $=\left[y 13\left(v, v^{\prime}, h, t\right): y 13\left(v, v^{\prime}, h, t\right) \in R^{+}\right.$, $\left.v \in M S, v^{\prime} \in P, h \in H, t \in T\right]$;

- Y14 $=\left[y 14\left(v, v^{\prime}, h, t\right): y 14\left(v, v^{\prime}, h, t\right) \in R^{+}\right.$, $\left.v \in M S, v^{\prime} \in M S, h \in H, t \in T\right]$;

- $Y 1=[y 1(v): y 1(v) \in\{0,1\}, v \in M S]$

with the constraints:

- The production capacity of suppliers cannot be exceeded - suppliers can provide the raw material directly to the recipients or indirectly by the warehouses:

$\forall v \in D S, \forall h \in H, \forall t \in T$

$\sum_{v^{\prime} \in M S} y 11\left(v, v^{\prime}, h, t\right)+$

$\sum_{v^{\prime} \in P} y 12\left(v, v^{\prime}, h, t\right) \leq q 1(v, h, t)$

- Recipients demands must be met - the raw material can flow to the recipients from suppliers or warehouses:

$\forall v^{\prime} \in P, \forall h \in H, \forall t \in T$

$\sum_{v \in M S} y 13\left(v, v^{\prime}, h, t\right)+$

$\sum_{v \in D S} y 12\left(v, v^{\prime}, h, t\right)=q 2\left(v^{\prime}, h, t\right) ;$

- Warehouses capacity cannot be exceeded - the raw material can flow to the warehouses from suppliers or other warehouses:

$\forall v^{\prime} \in P, \forall t \in T$

$\sum_{h \in H} \sum_{v \in D S} y 11\left(v, v^{\prime}, h, t\right)+$

$\sum_{h \in H} \sum_{v \in M S, v \neq v^{\prime}} y 14\left(v, v^{\prime}, h, t\right)+$

$\sum_{h \in H} q 3\left(v^{\prime}, h, t\right) \leq \operatorname{poj} z\left(v^{\prime}\right)$

- The raw material flowing out from the warehouse cannot exceed the sum of the volume of the raw material which is stored in these warehouses and the volume of the raw material which flows into the warehouse:

$\forall v \in M S, \forall h \in H, \forall t \in T$

$\sum_{v^{\prime} \in P} y 13\left(v, v^{\prime}, h, t\right)+$ 


$$
\begin{aligned}
& \sum_{v^{\prime} \in M S, v \neq v^{\prime}} y 14\left(v, v^{\prime}, h, t\right) \leq \\
& q 3(v, h, t)+\sum_{v^{\prime} \in D S} y 11\left(v^{\prime}, v, h, t\right)+ \\
& \sum_{v^{\prime} \in M S, v \neq v^{\prime}} y 14\left(v^{\prime}, v, h, t\right) ;
\end{aligned}
$$

- The maximal processing capacity of warehouses cannot be exceeded:

$\forall v \in M S, \forall h \in H, \forall t \in T$

$$
\begin{aligned}
& \sum_{v \in D S} y 11\left(v, v^{\prime}, h, t\right)+ \\
& \sum_{v \in M S, v \neq v^{\prime}} y 14\left(v, v^{\prime}, h, t\right) \leq q 4(v, h, t) ;
\end{aligned}
$$

- The minimal stream of the raw material flowing into the warehouses decides about the choice of those warehouses to the logistic network:

$\forall v \in M S, \forall h \in H, \forall t \in T$

$$
\begin{aligned}
& \sum_{v \in D S} y 11\left(v, v^{\prime}, h, t\right)+ \\
& \sum_{v \in M S, v \neq v^{\prime}} y 14\left(v, v^{\prime}, h, t\right) \geq \delta\left(v^{\prime}, h\right),
\end{aligned}
$$

which minimize the following criteria functions:

- The criterion of transportation costs between the facilities of the logistic network:

$$
\begin{aligned}
& \sum_{v \in D S} \sum_{v^{\prime} \in M S} \sum_{h \in H} \sum_{t \in T} y 11\left(v, v^{\prime}, h, t\right) \times \\
& d 1\left(v, v^{\prime}\right) \cdot c\left(v, v^{\prime}, h\right)+ \\
& \sum_{v \in D S} \sum_{v^{\prime} \in P} \sum_{h \in H} \sum_{t \in T} y 12\left(v, v^{\prime}, h, t\right) \times \\
& d 2\left(v, v^{\prime}\right) \cdot c\left(v, v^{\prime}, h\right)+ \\
& \sum_{v \in M S} \sum_{v^{\prime} \in P} \sum_{h \in H} \sum_{t \in T} y 13\left(v, v^{\prime}, h, t\right) \times \\
& d 4\left(v, v^{\prime}\right) \cdot c\left(v, v^{\prime}, h\right) \rightarrow \min ;
\end{aligned}
$$

- The criterion of the transition of the raw material via the warehouses:

$$
\begin{aligned}
& \sum_{v \in D S} \sum_{v^{\prime} \in M S} \sum_{t \in T} \sum_{h \in H} y 11\left(v, v^{\prime}, h, t\right) \times \\
& k z\left(v^{\prime}, h\right)+ \\
& \sum_{v \in M S} \sum_{v^{\prime} \in M S, v \neq v^{\prime}} \sum_{t \in T} \sum_{h \in \mathrm{H}} y 14\left(v, v^{\prime}, h, t\right) \times \\
& k z\left(v^{\prime}, h\right) \rightarrow \min ;
\end{aligned}
$$

- The criterion of the fuel costs - suppliers implement the transport of raw materials directly to the company, indirectly to warehouses and from warehouses to the company. The total length of route is determined on the basis of the number of courses between facilities:

$F 3(Y 11, Y 12, Y 13, Y 14)=$

$\sum_{t \in T} \sum_{v \in D S} \sum_{v^{\prime} \in P} \sum_{p o j \in P O J}\left[2 \cdot\left[\frac{\left.\left.\mid \sum_{h \in H} \frac{y 12\left(v, v^{\prime}, h, t\right)}{n(p o j)}\right\rceil\right] \operatorname{veh}\left(v, v^{\prime}, p o j\right)}{\mid}\right]-1\right] \times$

$d 2\left(v, v^{\prime}\right) \cdot k z p(p o j)+$

$\sum_{t \in T} \sum_{v \in D S} \sum_{v^{\prime} \in M S} \sum_{p o j \in P O J}\left[2 \cdot\left[\frac{\left.\left.\mid \sum_{h \in H} \frac{y 11\left(v, v^{\prime}, h, t\right)}{n(p o j)}\right\rceil\right]}{v e h\left(v, v^{\prime}, p o j\right)}\right]-1\right] \times$

$d 1\left(v, v^{\prime}\right) \cdot k z p(p o j)+$

$\sum_{t \in T} \sum_{v \in M S} \sum_{v^{\prime} \in P} \sum_{p o j \in P O J}\left[2 \cdot\left[\frac{\left\lceil\sum_{h \in H} \frac{y 13\left(v, v^{\prime}, h, t\right)}{n(p o j)}\right]}{v e h\left(v, v^{\prime}, p o j\right)}\right\rceil-1\right] \times$

$\sum_{t \in T} \sum_{v \in M S} \sum_{v^{\prime} \in M S, v \neq v^{\prime}} \sum_{p o j \in P O J}\left[2 \cdot\left[\frac{\left.\left.\mid \sum_{h \in H} \frac{y 14\left(v, v^{\prime}, h, t\right)}{n(p o j)}\right\rceil v^{\prime}\right) \cdot k z p(p o j)+}{v e h\left(v, v^{\prime}, p o j\right)}\right]-1\right] \times$

$d 4\left(v, v^{\prime}\right) \cdot k z p(p o j) \rightarrow \min ;$

- The criterion of the additional costs associated with warehouses, e.g.: local taxes, expenditure on starting the warehouse, the constant costs, the labour force costs, the purchase costs of the additional land for the expansion:

$F 4(Y 1)=$

$$
\begin{aligned}
& \sum_{v \in M S} y 1(v) \cdot(k l z(v)+k l z 1(v)+ \\
& k l z 2(v)+k l z 3(v)+k l z 4(v)) \rightarrow \min
\end{aligned}
$$

- The criterion associated with the distance of warehouses from the railway infrastructure:

$$
F 5(Y 1)=\sum_{v \in M S} y 1(v) \cdot d y 1(v) \rightarrow \min
$$

- The criterion associated with the distance of warehouses from of road infrastructure:

$$
F 6(Y 1)=\sum_{v \in M S} y 1(v) \cdot d k 1(v) \rightarrow \min ;
$$




\section{Genetic algorithm for multi-criteria warehouses location problem}

A genetic algorithm was used to determine the volume of the raw material, which flows between particular facilities in the network. On the basis of this volume, taking into account the constraints (1)-(6) and the criterion functions (7)-(12), the warehouse's location is determined. To form a genetic algorithm it is advisable to define the chromosome structure, the adaptation function, cross-linking process and mutation (Michalewicz 1996). The crossover process and mutation are reiterated a given number of times, until the stop condition has been achieved. A condition for stop in the developed algorithm is the fixed iterations number. In the selection process, the roulette method was adopted, while the process of cross-linking and mutation occurs with a defined likelihood set at the beginning of functioning of an algorithm. In order to prevent early convergence of the algorithm linear scaling was used (Goldberg 2003).

\subsection{Chromosome structure}

The structure of input data was presented as matrices $M(t, h)$, which present the flow of the raw materials between particular elements of the logistics network on a given working day. Lines and columns of those matrices define facilities of the logistic network structure. In order to determine the flow of the raw material, lines were defined as the starting points from which the raw material flows out to the other facilities. Matrix cells are located in the following sequence: suppliers, warehouses and production companies. The graphical representation of the matrix structure $M(t, h)$ with sample volumes was shown on Figure 1 ( $D S$ - suppliers, $M S$ - warehouses, $P$ - recipients-production companies). On the basis of volumes in the matrix $M(t, h)$, all criterion functions presented in the chapter 1 can be calculated, e.g. the decision variable which determines the raw material flow between DS1 and $M S 1$ takes the value 7 and consequently the binary decision variable for the warehouse MS1 takes the value 1 .

The key issue is to determine the correct structure processed by the algorithm that would meet limitations of the mathematical model. The steps of the procedure, which designates the initial structure for the first working day $(t=1)$ and the first type of the raw material $(h=1)$ can be presented as follows:

- Step 1: setting the values of all cells of the matrix on 0 . This value determines the connections for which it is not possible to transport the raw material, e.g. between suppliers.

- Step 2: randomly designating the values of cells for connections: suppliers - warehouses (DS1 (the row), MS1 (the column) - DS2 (the row), MS3 (the column)), Figure 2. The values of cells must meet the restrictions: the production capacity of suppliers (1) and warehouses capacity (3) cannot be exceeded. Among those constraints, the minimum value is se- lected. The value with the range of zero to this minimum value is randomly selected and put in the cells of the matrix. It should be remembered that in each cell the production capacity of suppliers and warehouses capacity need to be actualized.

- Step 3: checking the volumes of the raw material, which flows into the warehouses, e.g. the warehouse MS1 (the column) after the step 2 contains 12 raw materials. In this step, the constraints are checked: the maximal processing capacity (5) and the minimal stream of the raw material flowing into the warehouses (6). In case when one of these constraints is not fulfilled, the whole column for the given warehouse takes the value 0 .

- Step 4: randomly designating the values of cells for the connections: warehouses - production companies (MS1 (the row), P6 (the column) - MS3 (the row), $P 7$ (the column)). In this step, the constraints are checked: the raw material flowing out from the warehouses cannot exceed the volume of the raw material, which is stored in these warehouses (4) and the flow of the raw materials between warehouses and the recipients must be lower than recipients demand or equal (13). The constraint (13) was introduced for need of constructing the matrix $M(t, h)$ :

$\forall v^{\prime} \in P, \forall h \in H, \forall t \in T$

$\sum_{v \in M S} y 13\left(v, v^{\prime}, h, t\right) \leq q 2(v, h, t)$.

The cells of the matrix are complemented in the following way. At the beginning the value of the raw material in each warehouse must be designated, e.g. this value in the warehouse MS1 (the column) is equals 12. Next the demand of companies must be determined, e.g. 40 for P6. The next step is to select the minimal value from 12 and 40 . The value with the range of zero to this minimum value is randomly selected and put to the cell MS1, P6 of the matrix. Other cells are designated in the same way remembering that the volume of the raw materials in the warehouses and the demand of companies must be actualized.

- Step 5: designating the values of cells on the connections: suppliers - production companies (DS1 (row),

\begin{tabular}{|c|c|c|c|c|c|c|c|}
\cline { 2 - 8 } \multicolumn{1}{c|}{} & DS1 & DS2 & MS1 & MS2 & MS3 & P6 & P7 \\
\hline DS1 & 0 & 0 & 7 & 5 & 10 & 10 & 10 \\
\hline DS2 & 0 & 0 & 5 & 3 & 15 & 5 & 5 \\
\hline MS1 & 0 & 0 & 0 & 3 & 3 & 5 & 5 \\
\hline MS2 & 0 & 0 & 0 & 0 & 2 & 2 & 5 \\
\hline MS3 & 0 & 0 & 0 & 1 & 0 & 8 & 20 \\
\hline P6 & 0 & 0 & 0 & 0 & 0 & 0 & 0 \\
\hline P7 & 0 & 0 & 0 & 0 & 0 & 0 & 0 \\
\hline
\end{tabular}

Figure 1. The structure of the chromosome (source: research by the authors) 
P6 (the column) - DS2 (the row), P7 (the column)). In this step, the constraints are checked: recipient's demand must be met (2) and the production capacity of suppliers cannot be exceeded (1). If the recipient's demand was met in the step 4 all cells take the value 0 . Designating the values of cells in a random way is not correct because this way does not guarantee the solution, which meets the demands of all companies. In this case, the cells are designated in the following way. At the beginning the deliver and the company are selected in a random way, e.g. $D 1$ (the deliver) and P6 (the company). The next step is to select the minimum value from values: the current demand of the company and production capacity of suppliers. This step is repeated until the demands of all companies are met.

- Step 6: randomly designating the values of cells for the connections: warehouses - warehouses MS1 (the row), MS1 (the column) - MS3 (the row), MS3 (the column)). In this step, the constraints are checked: warehouses capacity (3) cannot be exceeded. The volume of raw materials is selected in a random way with the range from zero to current stock status, e.g. in order to transport the raw materials from MS1 to MS2 the number within the range 0 to 12 must be selected. It is assumed that the transport of the same raw materials occurs only in one direction. In this situation, one of the two parts of the matrix is filled out (over or under the diagonal).

It should be emphasized that the presented process of generating the initial matrix is valid for the situation in which the production capacity of suppliers must be larger than recipients demand and warehouses capacity. For other types of the raw material, the matrices should be generated in the same way remembering that the capacity of the warehouses must be actualized for each type of the raw material. This process needs to be repeated for each working day taking into account the volume of the raw material, which was stored in the warehouses on previous days.

\subsection{Adaptation function}

On the basis of the adaptation function the genetic algorithms designate the final solution. The genetic algorithms look for the maximal solution. In order to take into account the mentioned aspect and different criterion functions the adaptation function for $k$ - the structure of matrix $M(t, h)$ must take the following form $(K=\{1, \ldots$, $k, \ldots, K\}$ - set of structures $M(t, h)$ in the population):

$$
\begin{aligned}
& F(k, t, h)= \\
& \frac{F 1 \mathrm{~min}}{F 1(k, t, h)}+\frac{F 2 \mathrm{~min}}{F 2(k, t, h)}+\frac{F 3 \mathrm{~min}}{F 3(k, t, h)}+ \\
& \frac{F 4 \min }{F 4(k, t, h)}+\frac{F 5 \min }{F 5(k, t, h)}+\frac{F 6 \min }{F 6(k, t, h)} \rightarrow \text { max. }
\end{aligned}
$$

All decision variables can be read with the matrix. In order to be able to add the values of all criterion functions the adaptation function needs to be presented as the sum of quotients where e.g.: $F 1 \mathrm{~min}$ determines the structure of the minimum value of the criterion function from the whole population in a given iteration of algorithm, $F 1(k, t, h)$ determines the value of criterion function for $k-$ the structure of matrix $M(t, h)$. The function $F 1(k, t, h)$ will reach the maximum value in the case where each function, e.g. $F 1(k, t, h)$ will reach $F 1$ min, $F 2(k, t, h)$ will reach $F 2$ min and so on. If the criterion function, e.g.: $F 1(k, t, h)$ looks after the maximum value, then the function $F(k, t, h)$ will be looking after the minimum value when the numerator determines the structure of the maximum value from the whole population.
Structure 1

\begin{tabular}{|c|c|c|c|c|c|c|c|}
\cline { 2 - 8 } \multicolumn{1}{c|}{} & 1 & 2 & 3 & 4 & 5 & 6 & 7 \\
\hline 1 & 0 & 0 & 7 & 5 & 10 & 10 & 5 \\
\hline 2 & 0 & 0 & 5 & 3 & 15 & 5 & 5 \\
\hline 3 & 0 & 0 & 0 & 3 & 3 & 5 & 5 \\
\hline 4 & 0 & 0 & 3 & 0 & 2 & 2 & 5 \\
\hline 5 & 0 & 0 & 1 & 1 & 0 & 8 & 20 \\
\hline 6 & 0 & 0 & 0 & 0 & 0 & 0 & 0 \\
\hline 7 & 0 & 0 & 0 & 0 & 0 & 0 & 0 \\
\hline
\end{tabular}

Structure 2

\begin{tabular}{|c|c|c|c|c|c|c|c|}
\cline { 2 - 8 } \multicolumn{1}{c|}{} & 1 & 2 & 3 & 4 & 5 & 6 & 7 \\
\hline 1 & 0 & 0 & 7 & 5 & 10 & 10 & 5 \\
\hline 2 & 0 & 0 & 5 & 3 & 15 & 7 & 3 \\
\hline 3 & 0 & 0 & 0 & 2 & 4 & 3 & 7 \\
\hline 4 & 0 & 0 & 3 & 1 & 1 & 2 & 5 \\
\hline 5 & 0 & 0 & 1 & 1 & 0 & 8 & 20 \\
\hline 6 & 0 & 0 & 0 & 0 & 0 & 0 & 0 \\
\hline 7 & 0 & 0 & 0 & 0 & 0 & 0 & 0 \\
\hline
\end{tabular}

DIV

\begin{tabular}{|c|c|c|c|c|c|c|c|}
\cline { 2 - 8 } \multicolumn{1}{c|}{} & 1 & 2 & 3 & 4 & 5 & 6 & 7 \\
\hline 1 & 0 & 0 & 7 & 5 & 10 & 10 & 5 \\
\hline 2 & 0 & 0 & 5 & 3 & 15 & 6 & 4 \\
\hline 3 & 0 & 0 & 0 & 2 & 3 & 4 & 6 \\
\hline 4 & 0 & 0 & 3 & 0 & 1 & 2 & 5 \\
\hline 5 & 0 & 0 & 1 & 1 & 0 & 8 & 20 \\
\hline 6 & 0 & 0 & 0 & 0 & 0 & 0 & 0 \\
\hline 7 & 0 & 0 & 0 & 0 & 0 & 0 & 0 \\
\hline
\end{tabular}

REM

\begin{tabular}{|l|l|l|l|l|l|l|l|}
\cline { 2 - 8 } \multicolumn{1}{c|}{} & 1 & 2 & 3 & 4 & 5 & 6 & 7 \\
\hline 1 & 0 & 0 & 0 & 0 & 0 & 0 & 0 \\
\hline 2 & 0 & 0 & 0 & 0 & 0 & 0 & 0 \\
\hline 3 & 0 & 0 & 0 & 1 & 1 & 0 & 0 \\
\hline 4 & 0 & 0 & 0 & 1 & 1 & 0 & 0 \\
\hline 5 & 0 & 0 & 0 & 0 & 0 & 0 & 0 \\
\hline 6 & 0 & 0 & 0 & 0 & 0 & 0 & 0 \\
\hline 7 & 0 & 0 & 0 & 0 & 0 & 0 & 0 \\
\hline
\end{tabular}

New structure 1

\begin{tabular}{|c|c|c|c|c|c|c|c|}
\cline { 2 - 8 } \multicolumn{1}{c|}{} & 1 & 2 & 3 & 4 & 5 & 6 & 7 \\
\hline 1 & 0 & 0 & 7 & 5 & 10 & 10 & 5 \\
\hline 2 & 0 & 0 & 5 & 3 & 15 & 6 & 4 \\
\hline 3 & 0 & 0 & 0 & 3 & 3 & 4 & 6 \\
\hline 4 & 0 & 0 & 3 & 0 & 2 & 2 & 5 \\
\hline 5 & 0 & 0 & 1 & 1 & 0 & 8 & 20 \\
\hline 6 & 0 & 0 & 0 & 0 & 0 & 0 & 0 \\
\hline 7 & 0 & 0 & 0 & 0 & 0 & 0 & 0 \\
\hline
\end{tabular}

New structure 2

\begin{tabular}{|c|c|c|c|c|c|c|c|}
\cline { 2 - 8 } \multicolumn{1}{c|}{} & 1 & 2 & 3 & 4 & 5 & 6 & 7 \\
\hline 1 & 0 & 0 & 7 & 5 & 10 & 10 & 5 \\
\hline 2 & 0 & 0 & 5 & 3 & 15 & 6 & 4 \\
\hline 3 & 0 & 0 & 0 & 2 & 4 & 4 & 6 \\
\hline 4 & 0 & 0 & 3 & 1 & 1 & 2 & 5 \\
\hline 5 & 0 & 0 & 1 & 1 & 0 & 8 & 20 \\
\hline 6 & 0 & 0 & 0 & 0 & 0 & 0 & 0 \\
\hline 7 & 0 & 0 & 0 & 0 & 0 & 0 & 0 \\
\hline
\end{tabular}

Figure 2. The crossover process (source: research by the authors) 


\subsection{Crossover operator}

The crossover operator is adequate to the adopted matrix structure. To implement the crossover process for each day $t$ and for each type $h$, two matrices are developed: $\operatorname{DIV}(t, h)$ and matrix $\operatorname{REM}(t, h)$. Assuming that the value of matrices $M 1(t, h)$ and $M 2(t, h)$ (parents) in all cells assume determination $m_{v, v^{\prime}, t, h^{\prime}}^{1}, m_{v, v^{\prime}, t, h}^{2}$ values of elements of matrices $\operatorname{DIV}(t, h)$ and $R E M(t, h)$ are calculated from the following dependencies:

$$
\begin{aligned}
& d i v_{v, v^{\prime}, t, h}=\left\lfloor\frac{m_{v, v^{\prime}, t, h}^{1}+m^{2}{ }_{v, v^{\prime}, t, h}}{2}\right\rfloor ; \\
& r e m_{v, v^{\prime}, t, h}=\frac{m_{v, v^{\prime}, t, h}^{1}+m_{v, v^{\prime}, t, h}^{2}}{\bmod 2} .
\end{aligned}
$$

The full description of the crossover operator process was presented in (Michalczewski 1996) and presented in a graphical way to Figure 2. The values with the matrix REM are added to the matrix $D I V$. As a result, of this operation two new structures are developed. The applied crossover operator guarantees the correctness of individuals following a completed crossover, without the necessity of using repair algorithms.

\subsection{Mutation operator}

The operation rule of mutation operator consists of sampling of two figures $p$ and $q$ from the range: $2 \leq p \leq k$ and $2 \leq q \leq n$, which determine the number of lines and columns of a sub-matrix with dimensions $p \times q(k$ - number of lines in the main matrix (processed by the algorithm), $n$ - number of columns in this matrix). The generated matrix is modified in such a way that the total value in columns and lines before and after the modification process is not changed. The detailed mutation process has been outlined in (Michalewicz 1996) and in a graphical way it was presented on Figure 3.

The final effect of the genetic algorithm is matrix $M(t, h)$ for one type of the raw material $(h=1)$ and one day of work $(t=1)$. For other types of the raw material and days another matrices must be designated. The final matrix for a given working day is the matrix which contains the sum of the value of each matrix $M(t, h)$ for all types of the raw materials. On the basis of this matrix, the warehouses location is determined for a given working day.

\section{Implementation of genetic algorithm}

The first step of implementation of the genetic algorithm was to find the set of the best parameters, which characterizes this algorithm. The following combinations of parameters were analysed: $p_{\text {cross }}-$ crossover parameter, $p_{\text {mut }}-$ mutation parameter (Table 1 ). The number of iterations was set to 200. The linear scaling factor for the genetic algorithm accordance with the recommendations of the literature (Goldberg 2003) assumes the value 2.0. The adaptation function (14) was multiplied by the value 10000 in order to clearly present its results. The genetic algorithm was implemented by the use of the sample data input. One type of the raw material was took into account during implementation of the algorithm.

The graphical presentation of the results of tests of parameters was shown on Figure 4.

\begin{tabular}{c|c|c|c|c|c|c|c|}
\multicolumn{1}{c|}{ Matrix } \\
\cline { 2 - 9 } \multicolumn{1}{c|}{} & 1 & 2 & 3 & 4 & 5 & 6 & 7 \\
\hline 1 & 0 & 0 & 7 & 5 & 10 & 10 & 5 \\
\hline 2 & 0 & 0 & 5 & 3 & 15 & 6 & 4 \\
\hline 3 & 0 & 0 & 0 & 3 & 3 & 4 & 6 \\
\hline 4 & 0 & 0 & 3 & 0 & 2 & 2 & 5 \\
\hline 5 & 0 & 0 & 1 & 1 & 0 & 8 & 20 \\
\hline 6 & 0 & 0 & 0 & 0 & 0 & 0 & 0 \\
\hline 7 & 0 & 0 & 0 & 0 & 0 & 0 & 0 \\
\hline
\end{tabular}

Sub-matrix

\begin{tabular}{|c|c|c|}
\hline 3 & 4 & 5 \\
\hline 7 & 5 & 10 \\
\hline 5 & 3 & 15 \\
\hline 7 & 5 & 10 \\
\hline
\end{tabular}

Modification

\begin{tabular}{|c|c|c|}
\hline 3 & 4 & 5 \\
\hline 6 & 6 & 10 \\
\hline 6 & 2 & 15 \\
\hline 7 & 5 & 10 \\
\hline
\end{tabular}

Mutation

\begin{tabular}{|c|c|c|c|c|c|c|c|}
\cline { 2 - 8 } \multicolumn{1}{c|}{} & 1 & 2 & 3 & 4 & 5 & 6 & 7 \\
\hline 1 & 0 & 0 & 6 & 6 & 10 & 10 & 5 \\
\hline 2 & 0 & 0 & 6 & 2 & 15 & 6 & 4 \\
\hline 3 & 0 & 0 & 0 & 5 & 10 & 4 & 6 \\
\hline 4 & 0 & 0 & 3 & 0 & 2 & 2 & 5 \\
\hline 5 & 0 & 0 & 1 & 1 & 0 & 8 & 20 \\
\hline 6 & 0 & 0 & 0 & 0 & 0 & 0 & 0 \\
\hline 7 & 0 & 0 & 0 & 0 & 0 & 0 & 0 \\
\hline
\end{tabular}

Figure 3. The mutation process (source: research by the authors)

a)

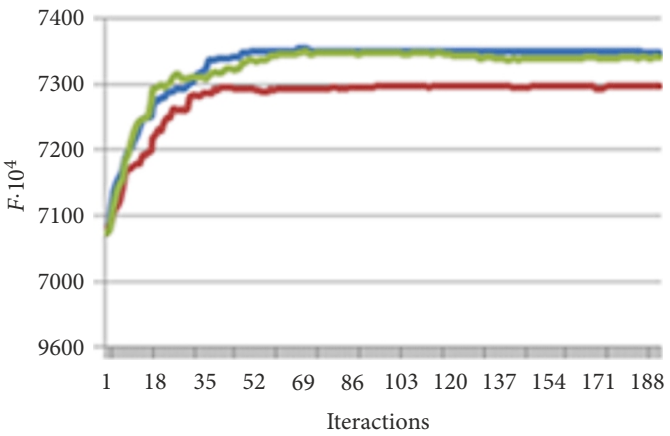

b)

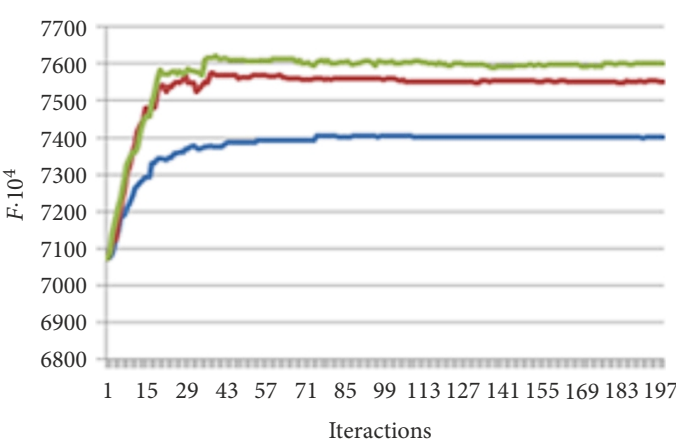

$p_{\text {mut }}=0.01$

$p_{\text {mut }}=0.03$

$p_{\text {mut }}=0.05$

Figure 4. The result of the genetic algorithm: a - test 2; b - test 14 (source: research by the authors) 
Table 1. The combination of the parameters (source: research by the authors)

\begin{tabular}{|c|c|c|}
\hline Test & $p_{\text {cross }}$ & $p_{\text {mut }}$ \\
\hline 1 & 0.2 & 0.01 \\
\hline 2 & 0.4 & 0.01 \\
\hline 3 & 0.6 & 0.01 \\
\hline 4 & 0.8 & 0.01 \\
\hline 5 & 1.0 & 0.01 \\
\hline 6 & 0.2 & 0.03 \\
\hline 7 & 0.4 & 0.03 \\
\hline 8 & 0.6 & 0.03 \\
\hline 9 & 0.8 & 0.03 \\
\hline 10 & 1.0 & 0.03 \\
\hline 11 & 0.2 & 0.05 \\
\hline 12 & 0.4 & 0.05 \\
\hline 13 & 0.6 & 0.05 \\
\hline 14 & 0.8 & 0.05 \\
\hline 15 & 1.0 & 0.05 \\
\hline
\end{tabular}

The results of all tests of parameters for the raw material was presented in Table 2.

Based on the results from Table 2, the optimal parameters were designated (test $14-p_{\text {cross }}=0.8, p_{\text {mut }}=0.05$ ). Different flow of the raw materials in the network was determined by the use of those parameters. In order to verify the correctness of the genetic algorithm (AG), its results were compared with random values $(\mathrm{AL})$. The genetic algorithm in each case generated a better solution than the random algorithm. The results are shown in Table 3.

\section{Conclusions}

The multi-criteria decision support in choosing the efficient location of warehouses in the logistic network is based on the work of the genetic algorithm.

The optimal results generated by the algorithm depend on many parameters, e.g.: mutation, crossover, the number of iterations or the size of the population. The selection of these parameters takes place in a random way.

In the implementation of the genetic algorithm, the different combinations of these parameters were examined, e.g.: 200 chromosomes (structures), 100 iterations. It should be emphasized that the generated solution by the genetic algorithm is sub - optimal. In spite of this, the speed of the algorithm is its advantage.

Further research in the context of the use of the genetic algorithm in the multi-criteria decision support in choosing the efficient location of warehouses will be conducted using other selection methods described in the literature. Fast time of generating the result by this algorithm is its main feature, what is desired by the companies located in the logistic network.

The algorithm for designating warehouse locationrouting problem must be adapted to frequent changes of
Table 3. Comparison of algorithms (source: research by the authors)

\begin{tabular}{|c|c|c|}
\hline Test & AG & AL \\
\hline 1 & 7800 & 28265 \\
\hline 2 & 8020 & 28640 \\
\hline 3 & 11310 & 27650 \\
\hline 4 & 11370 & 26975 \\
\hline 5 & 9985 & 28680 \\
\hline 6 & 7540 & 28105 \\
\hline 7 & 11840 & 27649 \\
\hline 8 & 9950 & 27615 \\
\hline 9 & 8355 & 28155 \\
\hline 10 & 7960 & 27949 \\
\hline 11 & 13485 & 28200 \\
\hline 12 & 7085 & 27455 \\
\hline 13 & 8685 & 27470 \\
\hline 14 & 8375 & 27280 \\
\hline 15 & 6825 & 28175 \\
\hline
\end{tabular}

factors, e.g. processing capacity of companies, the production capacities of suppliers and generate the solutions in a quickly way. It should be underlined that results of the genetic algorithm depend on the type of the data input which are took into account in the mathematical model.

The algorithm was implemented by the use of the fixed data input, e.g. the distance between the objects.

The presented model does not take into account the random values of the input data, e.g. the delivery time.

Further research in the context of the genetic algorithm and multi-criteria warehouse location problem will be conducted taking into account random character of transport process, e.g. random input data can be generated by the use of the artificial neural network.

The developed algorithm can be used in production companies to develop the driver's working schedules, the minimal number of vehicles, which realize given transportation tasks.

This algorithm cannot be used in the production companies in which time windows of delivery are determined.

The processes occurring in the production companies are the dynamic processes. For this reason, the genetic algorithm must be started several times depending on recipients demands, warehouses capacities. In this case, the calculation speed plays the huge role what underlines utility of this algorithm in the production companies.

\section{Funding}

The scientific work carried out in the frame of PBS 3 project "System for modelling and 3D visualization of storage facilities" (SIMMAG 3D) PBS3/B6/22/2015 financed by the National Centre for Research and Development (Poland). 


\section{Contribution}

Mariusz Izdebski, Ilona Jacyna-Gołda - 25\% each of them (developing the genetic algorithm, implementation).

Mariusz Wasiak, Roland Jachimowski, Michał Kłodawski, Dariusz Pyza, Jolanta Żak - 10\% each of them (developing the mathematical model, analysis of the problem).

\section{Disclosure statement}

Authors don't have any competing financial, professional, or personal interests from other parties.

\section{References}

Akinc, U.; Khumawala, B. M. 1977. An efficient branch and bound algorithm for the capacitated warehouse location problem, Management Science 23(6): 585-594. https://doi.org/10.1287/mnsc.23.6.585

Ambroziak, T.; Jacyna, M.; Wasiak, M. 2006. The logistic services in a hierarchical distribution system, in K. G. Goulias (Ed.). Transport Science and Technology, 383-394. https://doi.org/10.1108/9780080467542-030

Brandeau, M. L.; Chiu, S. S. 1989. An overview of representative problems in location research, Management Science 35(6): 645-674. https://doi.org/10.1287/mnsc.35.6.645

Demirel, T.; Demirel, N. Ç.; Kahraman, C. 2010. Multi-criteria warehouse location selection using Choquet integral, Expert Systems with Applications 37(5): 3943-3952.

https://doi.org/10.1016/j.eswa.2009.11.022

Dey, B.; Bairagi, B.; Sarkar, D.; Sanyal, S. K. 2016. Warehouse location selection by fuzzy multi-criteria decision making methodologies based on subjective and objective criteria, International Journal of Management Science and Engineering Management 11(4) 262-278.

https://doi.org/10.1080/17509653.2015.1086964

Geoffrion, A. M.; Graves, G. W. 2010. Multicommodity distribution system design by benders decomposition, International Series in Operations Research \& Management Science 148: 35-61. https://doi.org/10.1007/978-1-4419-6810-4_4

Goldberg, D. E. 2003. Algorytmy genetyczne $i$ ich zastosowania, Warszawa: Wydawnictwa naukowo-techniczne. 408 s. (in Polish).

Gołda, P.; Manerowski, J. 2014. Support of aircraft taxiing operations on the apron, Journal of Kones Powertrain and Transport 21(4): 127-135. https://doi.org/10.5604/12314005.1130457

Izdebski, M.; Jacyna-Gołda I.; Wasiak M. 2016. The application of genetic algorithm for warehouse location in logistic network, Journal of Kones Powertrain and Transport 23(3): 201-208. https://doi.org/10.5604/12314005.1216464

Jacyna, M. 1999. Multicriteria evaluation of traffic flow distribution in a multimodal transport corridor, taking into account logistics base service, Archives of Transport 11(3-4): 43-66.

Jacyna, M.; Wasiak, M. 2015. Multicriteria decision support in designing transport systems, Communications in Computer and Information Science 531: 11-23.

https://doi.org/10.1007/978-3-319-24577-5_2

Jacyna-Gołda, I. 2013. Chosen aspects of logistics network design method for production service companies, International Journal of Logistics Systems and Management 15(2/3): 219238. https://doi.org/10.1504/IJLSM.2013.053768
Jacyna-Gołda, I.; Izdebski, M.; Szczepański, E. 2016. Assessment of the method effectiveness for choosing the location of warehouses in the supply network, Communications in Computer and Information Science 640: 84-97.

https://doi.org/10.1007/978-3-319-49646-7_8

Khumawala, B. M. 1973. An efficient heuristic procedure for the uncapacitated warehouse location problem, Naval Research Logistics Quarterly 20(1): 109-121. https://doi.org/10.1002/nav.3800200111

Lewczuk, K. 2015. The concept of genetic programming in organizing internal transport processes, Archives of Transport 34(2): 61-74. https://doi.org/10.5604/08669546.1169213

Merkisz-Guranowska, A.; Pielecha, J. 2014. Passenger cars and heavy duty vehicles exhaust emissions under real driving condition, Archives of Transport 31(3): 47-59. https://doi.org/10.5604/08669546.1146986

Michalewicz, Z. 1996. Algorytmy genetyczne + struktury danych = programy ewolucyjne. Warszawa: Wydawnictwa naukowo-techniczne. 432 s. (in Polish).

Özcan, T.; Çelebi, N.; Esnaf, Ş. 2011. Comparative analysis of multi-criteria decision making methodologies and implementation of a warehouse location selection problem, Expert Systems with Applications 38(8): 9773-9779.

https://doi.org/10.1016/j.eswa.2011.02.022

Podviezko, A. 2012. Augmenting multicriteria decision aid methods by graphical and analytical reporting tools, Lecture Notes in Business Information Processing 106: 236-251. https://doi.org/10.1007/978-3-642-29231-6_19

Sharma, R. R. K. 1991. Modelling a fertiliser distribution system, European Journal of Operational Research 51(1): 24-34. https://doi.org/10.1016/0377-2217(91)90142-I

Sharma, R. R. K.; Berry, V. 2007. Developing new formulations and relaxations of single stage capacitated warehouse location problem (SSCWLP): Empirical investigation for assessing relative strengths and computational effort, European Journal of Operational Research 177(2): 803-812. https://doi.org/10.1016/j.ejor.2005.11.028

Szczepański, E.; Jacyna-Gołda, I.; Murawski J. 2014. Genetic algorithms based approach for transhipment HUB location in urban areas, Archives of Transport 31(3): 73-82. https://doi.org/10.5604/08669546.1146989

Wasiak, M.; Jacyna-Gołda, I.; Izdebski, M. 2016. Multi-criteria warehouses location problem in the logistics network, in International Conference on Industrial Logistics (ICIL 2016), 28 September - 1 October 2016, Zakopane, Poland, 352-363.

Zieja, M.; Smoliński, H.; Gołda, P. 2015. Information systems as a tool for supporting the management of aircraft flight safety, Archives of Transport 36(4): 67-76. https://doi.org/10.5604/08669546.1185211 